\title{
Microbial metabolite fluxes in a model marine anoxic ecosystem
}

\author{
Stilianos Louca ${ }^{1,2, *}$, Yrene M. Astor ${ }^{3,4}$, Michael Doebeli ${ }^{1,2,5}$, Gordon T. Taylor ${ }^{6}$ \& Mary I. Scranton ${ }^{6}$ \\ ${ }^{1}$ Biodiversity Research Centre, University of British Columbia, Canada \\ ${ }^{2}$ Department of Zoology, University of British Columbia, Canada \\ ${ }^{3}$ Estación de Investigaciones Marinas de Margarita, Fundación La Salle de Ciencias Naturales, Punta de Piedras, \\ Estado Nueva Esparta, Venezuela \\ ${ }^{4}$ Institute for Marine Remote Sensing, University of South Florida, USA \\ ${ }^{5}$ Department of Mathematics, University of British Columbia, Canada \\ ${ }^{6}$ School of Marine and Atmospheric Sciences, Stony Brook University, USA \\ *Corresponding author. Contact details at www.loucalab.com
}

\section{Keywords}

geobiology; redoxcline; inverse transport modeling; Cariaco Basin; chemolithoautotroph

\section{Acknowledgements}

S.L. was supported by an NSERC grant and a postdoctoral fellowship from the Biodiversity Research Centre, UBC. M.D. was supported by an NSERC Discovery Grant. We thank all participants and funders of the CARIACO Ocean Time Series program, including the US National Science Foundation for long-term support and in particular through NSF grant OCE-1259110 (to M.I.S. and G.T. Taylor), the Venezuelan Consejo Nacional de Investigaciones Cienti cas y Tecnológicas and the Venezuelan Fondo Nacional de Ciencia y Tecnología. We thank Christopher Wolfe and three anonymous reviewers for comments on our manuscript.

\section{Author contributions}

S.L. conceived the project, wrote the computer code, performed the analyses and wrote a first draft of the manuscript. M.I.S., G.T.T. and Y.M.A. were some of the coordinators of the CARIACO Ocean Time Series program. All authors helped interpret the results, and contributed to the writing of the manuscript. 


\begin{abstract}
Permanently anoxic regions in the ocean are widespread, and exhibit unique microbial metabolic activity exerting substantial influence on global elemental cycles and climate. Reconstructing microbial metabolic activity rates in these regions has been challenging, due to the technical difficulty of direct rate measurements. In Cariaco Basin, which is the largest permanently anoxic marine basin and an important model system for geobiology, long-term monitoring has yielded time series for the concentrations of biologically important compounds; however the underlying metabolite fluxes remain poorly quantified. Here we present a computational approach for reconstructing vertical fluxes and in situ net production/consumption rates from chemical concentration data, based on a 1-dimensional time-dependent diffusive transport model that includes adaptive penalization of overfitting. We use this approach to estimate spatiotemporally resolved fluxes of oxygen, nitrate, hydrogen sulfide, ammonium, methane and phosphate within the sub-euphotic Cariaco Basin water column (depths 150-900 m, years 2001-2014), and to identify hotspots of microbial chemolithotrophic activity. Predictions of the fitted models are in excellent agreement with the data, and substantially expand our knowledge of the geobiology in Cariaco Basin. In particular, we find that the diffusivity, and consequently fluxes of major reductants such as hydrogen sulfide and methane, are about two orders of magnitude greater than previously estimated, thus resolving a long standing apparent conundrum between electron donor fluxes and measured dark carbon assimilation rates.
\end{abstract}

Abbreviations: ILTM, inverse linear transport modeling; DCA, dark carbon assimilation

\title{
1 Introduction
}

Permanently or temporarily anoxic regions in the ocean are a topic of increasing interest due to their unique microbial ecology (Wright et al., 2012; Ulloa et al., 2013), their importance to global elemental cycles and marine productivity (Ulloa et al., 2012), and the intensifying deoxygenation of the ocean (Schmidtko et al., 2017; Breitburg et al., 2018). Microorganisms in these regions are adapted to operate under oxygen-limited or oxygen-depleted conditions, making use of alternative terminal electron acceptors for respiration and often utilizing inorganic substrates for energy. In many anoxic marine zones, reductants such as hydrogen sulfide, ammonium and the potent greenhouse gas methane, diffusing upwards from underlying layers or the sediments, react biologically with oxidants such as oxygen and nitrate produced in the overlying layers, thus fueling chemolithoautotrophic activity and affecting marine nitrogen, sulfur, oxygen and carbon budgets (Ulloa et al., 2012; Taylor et al., 2018). In the Cariaco Basin, a permanently anoxic marine region off the coast of Venezuela, multi-decadal monitoring has generated rich time series of the distribution of metabolically important compounds over space and time (Scranton et al., 2014; Muller-Karger et al., 2019). These data revealed the existence of a strong dynamic redox gradient over depth, along which upward diffusing reductants such as hydrogen sulfide are directly or indirectly oxidized by oxidants such as oxygen in a transition zone roughly spanning depths 200-400 m, sometimes referred to as "redoxcline" (Ho et al., 2004; Li et al., 2012b; Taylor et al., 2018). Concurrent molecular surveys revealed unique microbial communities that exhibit a clear spatial organization across depth, and elevated population densities within the redoxcline 
(Taylor et al., 2006; Rodriguez-Mora et al., 2015; Taylor et al., 2018; Cernadas-Martín et al., 2017; Suter et al., 2018). However, chemical fluxes across space and microbial metabolic rates in Cariaco Basin and other anoxic regions remain poorly quantified and are largely temporally unresolved, thus making a mechanistic connection between chemical transitions and microbial ecological dynamics difficult (Taylor et al., 2018). A major reason for this gap in our knowledge is that, compared to chemical concentration measurements, explicit metabolic rate measurements are technically challenging, especially when performed in situ.

Mathematical modeling is sometimes used to indirectly estimate the flux rates that underly the observed chemical concentrations (Scranton et al., 1987; Berg et al., 1998; Taylor et al., 2001; Samodurov et al., 2013; Li et al., 2012b; Cernadas-Martín et al., 2017; Taylor et al., 2018). For example, Scranton et al. (1987) used a time-dependent diffusion box model to estimate sulfide fluxes from the sediments into the Cariaco Basin water column. These calculations, however, were based solely on measurements at two time points (in 1973 and 1982), ignored possible in situ sulfide production (Li et al., 2012b), and assumed that sulfide was consumed entirely at some fixed depth, thus ignoring shifts in the redoxcline depth over time (Scranton et al., 2014). On the other hand, Li et al. (2012b) and Cernadas-Martín et al. (2017) used a 1-dimensional diffusion model for Cariaco Basin to estimate fluxes of various compounds produced or consumed during microbial metabolism (henceforth "metabolites" for simplicity). Their models only estimated fluxes into and out of a narrow depth interval ( $\sim 100-200 \mathrm{~m}$ wide), thus missing possible metabolic activity at other depths, and assumed that metabolite depth profiles were at steady state, thus ignoring possible temporal lags in the response of redox gradients to flux changes (Scranton et al., 1987, 2014) and microbial dynamics (Taylor et al., 2018).

Here we develop a computational approach for estimating metabolite fluxes and net production/consumption rates across space and time, using chemical concentration data measured at arbitrary spacetime points. Our approach is based on a 1-dimensional time- and depth-dependent diffusive transport model that accounts for temporal changes in boundary conditions, diffusive transport coefficients and in situ production rates, as well as for potential geometric dilution effects due to variation of a system's lateral (cross-sectional) area with depth. We use our approach to reconstruct spatiotemporally resolved metabolite fluxes across the subeuphotic Cariaco Basin water column (depths 150-900 m) during the years 2001-2014. We consider several important metabolites, including oxygen $\left(\mathrm{O}_{2}\right)$, nitrate $\left(\mathrm{NO}_{3}^{-}\right)$, hydrogen sulfide $\left(\mathrm{H}_{2} \mathrm{~S}\right)$, ammonium $\left(\mathrm{NH}_{4}^{+}\right)$, methane $\left(\mathrm{CH}_{4}\right)$ and phosphate $\left(\mathrm{PO}_{4}^{3-}\right)$. Our estimates yield detailed insight into the microbial activity that underlies the geochemical structure of the Cariaco Basin water column.

\section{Results and Discussion}

\subsection{Estimating diffusivity over space and time}

In largely stagnant marine basins such as Cariaco Basin (Scranton et al., 1987; Samodurov et al., 2013; Taylor et al., 2018), the Black Sea (Ivanov and Samodurov, 2001) and parts of the Arabian Sea (Lam et al., 2011), eddy (turbulent) diffusion is the dominant mode of vertical transport of dissolved metabolites. Great 
uncertainty often exists over the magnitude of the vertical diffusion coefficient (henceforth "diffusivity"), and this uncertainty can substantially influence flux estimates. Previous theoretical and empirical work suggests that the diffusivity (denoted $D$ ) in such water columns is typically related to the buoyancy frequency (denoted $N)$ through a power-law relationship of the form:

$$
D(t, z)=\alpha N(t, z)^{-p}
$$

where $t$ is time, $z$ is depth, and $\alpha$ and $p$ are system-specific parameters (Sarmiento et al., 1976; Gregg, 1977; Armi, 1979; Smethie, 1980; Osborn, 1980; Gargett and Holloway, 1984; Gargett, 1984; Gregg et al., 1986). Such a power law can be mathematically justified for stably stratified systems without double diffusion and in which the bulk of kinetic energy reaches turbulent scales via internal waves (Gargett, 1984). In these scenarios, the parameter $\alpha$ accounts for the average energy entering the system (e.g., by winds or tides), and $p$ (typically between 0.5 and 1 ) reflects the a priori unknown $N$-dependence of internal wave velocity variances (Gargett, 1984). Alternatively, a power law can be derived for stably stratified systems in which an apparent diapycnal diffusion-like mixing is caused mainly by turbulence near the basin bottom/boundaries and topographic features and a rapid redistribution of material throughout the interior by isopycnal advection (Armi, 1979), yielding $p \approx 2$. In some studies, a power law relationship between $D$ and $N$ is a purely empirical observation, with $p$ ranging between 0.5 and 2 (Sarmiento et al., 1976; Svensson, 1980; Gargett, 1984). We mention that alternative $N$-dependent models for $D$ have also been derived, based on different assumptions regarding the origin and dissipative nature of kinetic energy (Munk and Anderson, 1948; Lee et al., 2006; Olbers and Eden, 2013).

Equation (1) has been used extensively to predict turbulent transport of dissolved gases and salts in various systems, especially in anoxic marine systems (Fennel and Boss, 2003; Ho et al., 2004; Li et al., 2012b; Samodurov et al., 2013; Reed et al., 2014; Louca et al., 2016). The buoyancy frequency $N$ can be calculated from the measured salinity and temperature profiles, however the appropriate values for $\alpha$ and $p$ are typically poorly constrained. Some studies have estimated the parameters $\alpha$ and $p$, or diffusivity itself, using spatiotemporal profiles of salinity (Gade, 1970; Smethie, 1980; Lewis and Perkin, 1982; Ivanov and Samodurov, 2001) or other conserved tracers (Svensson, 1980; Gargett, 1984). For example, Svensson (1980) used the diffusion of Rhodamine B as a semi-conserved tracer to estimate a power-law exponent of $p=1.2$ in Byfjorden (Sweden), Gade (1970) used the salt budget to estimate an exponent of $p=1.6$ in Oslofjord (Norway), and Lewis and Perkin (1982) used the salt budget to estimate $D$ in Agfardlikavsa Fjord (Greenland), revealing a power law dependence on $N$ with an exponent $p \approx 1.2$ (Gargett, 1984). In Cariaco Basin analogous parameter estimates are lacking, and previous studies simply assumed an exponent of $p=1$ (Scranton et al., 1987; Taylor et al., 2001; Ho et al., 2004; Li et al., 2012b; Samodurov et al., 2013; Taylor et al., 2018). A value of $p=1$ is also frequently assumed in other systems (Zopfi et al., 2001; Yakushev et al., 2007; Yakushev, 2013), although some studies instead assumed $p=2$ (Fennel and Boss, 2003; Reed et al., 2014). The factor $\alpha$ is usually chosen roughly based on estimates from other marine systems (Ho et al., 2004; Li et al., 2012b; Samodurov et al., 2013; Taylor et al., 2018).

Here, to estimate both $\alpha$ and $p$ for Cariaco Basin, thus resolving a major source of uncertainty in flux 
estimates, we used a 1-dimensional diffusive transport model for the salt budget in Cariaco Basin, and fitted the parameters $\alpha$ and $p$ by minimizing the deviation of the model predictions from salinity measurements. Specifically, for any given choice of $\alpha$ and $p$, we numerically solved the diffusion equation

$$
\frac{\partial \hat{S}}{\partial t}=\frac{\partial}{\partial z}\left[D(t, z) \frac{\partial \hat{S}}{\partial z}\right]+\frac{1}{A(z)} \frac{\partial A}{\partial z}\left[D(t, z) \frac{\partial \hat{S}}{\partial z}\right]
$$

where $\hat{S}$ is the predicted salinity, $D$ is the diffusivity calculated using Eq. (1) and $A(z)$ is the lateral (crosssectional) area of the basin at depth $z$ (Supplemental Fig. S.1). The last term in Eq. (2) accounts for geometric dilution effects due to variation of the basin area over depth (Samodurov et al., 2013). This model omits occasional lateral intrusions of Caribbean Sea water (Samodurov et al., 2013; Scranton et al., 2014); the accuracy of the model is assessed in retrospect. We considered the depth range 150-900 $\mathrm{m}$ and the period spanning years 2001-2014, with boundary conditions provided by measured salinities at $150 \mathrm{~m}$ and $900 \mathrm{~m}$. This depth range was chosen because $150 \mathrm{~m}$ is the maximum depth of the sill separating Cariaco Basin from the open ocean (and above which non-diffusive salt transport due to lateral currents is more pronounced), and because $900 \mathrm{~m}$ is the depth of the saddle that separates the west and east sub-basins in Cariaco (Taylor et al., 2001). The parameters $\alpha$ and $p$ were gradually adjusted using an optimization algorithm, so that the sum of squared deviations between $\hat{S}$ and the measured salinity is minimized. This yielded the estimates $\alpha=0.0001316$ and $p=1.7433$, when $D$ is measured in $\mathrm{cm}^{2} \cdot \mathrm{s}^{-1}$ and $N$ is measured in $\mathrm{s}^{-1}$. The agreement between the predicted and measured salinity profiles was excellent, as measured by the fraction of explained variance $\left(r^{2}=0.982\right.$, Supplemental Fig. S.3B). This suggests that neglected processes, such as occasional lateral water intrusions, only have a minor influence on the Cariaco Basin salt budget during the considered time interval.

To test whether our diffusivity estimates are sensitive to the choice of model, we also considered an alternative model known as Munk-Anderson scheme (Munk and Anderson, 1948; James, 1977; Lee et al., 2006):

$$
D(t, z)=D_{o} \cdot\left[1+\sigma \cdot N(t, z)^{2} \cdot 2 \frac{(H-z)^{2}}{B^{2}}\right]^{-Q},
$$

where $D_{o}, \sigma, Q$ and $B$ are system-specific model parameters and $H$ is the bottom depth $(H \approx 1400 \mathrm{~m}$ for Cariaco Basin). The Munk-Anderson scheme assumes that diffusion-like vertical mixing is driven by frictional velocity shear, induced by tidal motions damped near the basin bottom (Munk and Anderson, 1948). The specific formula in Eq. (3) is based on an empirical logarithmic profile of horizontal current velocities (James, 1977) and was used by Lee et al. (2006) in a North Atlantic ocean model. When we fit the above model to the salinity profiles in Cariaco Basin (depths 150-900 m, years 2001-2014), we obtained very similar diffusivity estimates as with the power law model (Supplemental Figs. S.4A,B). Further, when we combined both models into a single additive model (i.e., using the sum of Eq. 1 and Eq. 3), we again obtained similar diffusivity estimates as before (Supplemental Figs. S.4C,D). While our findings do not resolve which model provides the most suitable mechanistic explanation of mixing in Cariaco Basin, all models yield similar estimates for the effective diffusivity. 
To further confirm the robustness of our model-based estimates we also considered a model-independent approach, in which diffusivity is estimated directly from the salinity data $(S)$ regardless of the buoyancy frequency and without assuming a particular process as the cause of mixing (Fig. 1C, details in Supplement S.1). Briefly, this alternative approach assumes that $D$ is constant over time and somehow known at some given "anchor depth" $z_{a}$. In this case, $D(z)$ can be estimated using the implicit formula:

$$
\hat{D}(z)=\frac{1}{\partial_{z} U(z)} \cdot\left[M(z)+D\left(z_{a}\right)\left(\partial_{z} U\right)\left(z_{a}\right)-L(z)\right]
$$

where $M(z), U(z)$ and $L(z)$ are auxiliary quantities calculated using the salinity data, defined as follows:

$$
\begin{aligned}
& M(z)=\int_{z_{a}}^{z} d x\left[S\left(t_{2}, x\right)-S\left(t_{1}, x\right)\right], \\
& U(z)=\int_{t_{1}}^{t_{2}} d s S(s, z) \\
& L(z)=\int_{z_{a}}^{z} d x \hat{D}(x) \frac{\partial_{x} A}{A(x)} \partial_{x} U(x),
\end{aligned}
$$

and where $t_{1}<t_{2}$ are any two time points. The accuracy of the "anchored" estimate $\hat{D}$ defined in Eq. (4) improves for larger considered time spans $\left|t_{2}-t_{1}\right|$, and hence we used the full available time range (years 2001-2014). Because the auxiliary variable $L$ itself depends on the estimated diffusivity $\hat{D}$, an iterative approach was used to solve for $\hat{D}$. The choice of $z_{a}$ is in principle arbitrary, as long as $D\left(z_{a}\right)$ can be determined somehow. A similar approach was used previously by Samodurov et al. (2013) to estimate $D$ in Cariaco Basin, using the anchor depth $z_{a}=150 \mathrm{~m}$, with an important difference: Samodurov et al. estimated $D\left(z_{a}\right)$ using the buoyancy-frequency-based formula in Eq. (1), with $\alpha$ based on other marine systems and assuming $p=1$, whereas here we made no assumption about $D\left(z_{a}\right)$ and instead estimated $D\left(z_{a}\right)$ from the salinity data via least-squares fitting (details in Supplement S.1). We emphasize that this estimate is strictly speaking only valid if the true diffusivity $D$ does not vary with time, and hence it should only be used as a rough sanity check. This alternatively estimated diffusivity profile again closely reproduces the measured salinity profile ( $r^{2}=0.982$, Supplemental Fig. S.3C) and also approximately resembles our previous diffusivity estimates (Fig. 1B), further increasing our confidence in these estimates.

As seen in Fig. 1A, the estimated diffusivity increases drastically with depth, due to the decreased buoyancy frequency and the super-linear scaling of $D(p>1)$. Our diffusivity estimates, particularly those near the bottom, are substantially higher than typical diffusivities estimated in other fjords and basins (Gargett, 1984; Yakushev et al., 2007). In Cariaco Basin, stratification is extremely weak towards the bottom, allowing for more rapid diapycnal mixing than in the redoxcline. An exponent $p$ greater than 1 and closer to 2 also suggests that mixing in Cariaco Basin is largely driven by turbulence near the basin's boundaries (Armi, 1979), especially at depth where the lateral area decreases substantially (Supplemental Fig. S.1). Compared to other prominent anoxic marine systems, Cariaco Basin is relatively compact, with a horizontal area (at the sill's depth) about 40 times smaller than the Black Sea (Kideys, 2002) and the Baltic Sea (Leppäranta and Myrberg, 2009) and about 130 times smaller than the Arabian Sea (Goyet et al., 1998), potentially resulting 
in stronger boundary mixing than in those other systems. We point out that, in reality, the eddy diffusivity may exhibit substantial lateral heterogeneity, and may be greater near the Basin's walls than in the center. The diffusivity profile estimated here thus represents the effective (laterally averaged) diffusivity under a 1-dimensional transport model that describes laterally-averaged vertical fluxes. Such a model is itself only valid under the implicit assumption that lateral mixing is much faster than vertical mixing — a reasonable assumption for Cariaco Basin, since stratification is largely vertical.

Our diffusivity estimates are substantially higher than estimates from previous studies in Cariaco Basin, all of which assumed an exponent of $p=1$ (Scranton et al., 1987; Li et al., 2012b; Samodurov et al., 2013; Taylor et al., 2018). An exponent greater than $1(p \approx 1.7)$ is strongly supported by our fitted model, as the value $p=1$ results in a much lower goodness of fit (Supplemental Fig. S.13). An exponent $p>1$ is also consistent with our alternatively estimated diffusivity profiles (Fig. 1C and Supplemental Fig. S.4). Hence, previous studies probably underestimated $D$ in Cariaco Basin, especially in deeper waters. As we discuss below, this has substantial implications for metabolite flux estimates and may explain some of the apparent imbalances between metabolite supply and biological demand previously observed in Cariaco Basin.

\subsection{Inverse linear transport modeling}

Our approach for estimating vertical fluxes and volume-specific net production rates of dissolved metabolites is based on the following 1-dimensional reaction-diffusion differential equation for the metabolite's volumetric concentration:

$$
\frac{\partial C}{\partial t}=\frac{\partial}{\partial z}\left[D(t, z) \cdot \frac{\partial C}{\partial z}\right]+\frac{1}{A(z)} \frac{\partial A}{\partial z}\left[D(t, z) \cdot \frac{\partial C}{\partial z}\right]+R(t, z) .
$$

Here, $C(t, z)$ is the metabolite's concentration $\left(\mathrm{mol} \cdot \mathrm{L}^{-1}\right), D(t, z)$ is the diffusivity (e.g., as estimated above), $A(z)$ is the lateral (cross-sectional) area of the basin and $R(t, z)$ is the a priori unknown volume-specific net metabolite production rate at any time $t$ and depth $z$. Similarly to the salinity model above, this model can account for geometric dilution effects due to variations of the lateral basin area with depth (Samodurov et al., 2013). Variants of the above model have been used extensively to describe dissolved nutrient transport in Cariaco Basin (Scranton et al., 1987; Li et al., 2012b; Cernadas-Martín et al., 2017; Taylor et al., 2018), although previous studies made simplifying assumptions such as that $R$ was negligible (Scranton et al., 1987), that $D$ was constant over time (Li et al., 2012b; Taylor et al., 2018) or that $C$ was at steady state (i.e., $\partial C / \partial t=0$; Li et al., 2012b; Cernadas-Martín et al., 2017; Taylor et al., 2018). Since $C$ has been measured and $D$ has been previously estimated, in principle one could directly calculate the unknown rate $R$ at various times and depths through a simple algebraic reordering of Eq. (6). Unfortunately, this approach generally suffers from high estimation errors. The main reason is that the numerical estimation of spatial derivatives from discrete depth profiles, or of temporal derivatives from discrete time series, typically leads to an amplification of high-frequency noise (Knowles and Renka, 2014).

An alternative approach for estimating $R$ that reduces estimation noise and avoids the risk of overfitting is 
to choose $R$ on a finite spatiotemporal grid ("fitting grid"), such that the corresponding predicted distribution $\hat{C}$ obtained by solving the differential equation (6) best matches the observed profile $C$. This approach, known as "inverse linear transport modeling" (ILTM), is widely used in oceanography and atmospheric sciences, where known distributions of compounds are used to estimate unknown sources and sinks (Berg et al., 1998; Houweling et al., 1999; Mikaloff Fletcher et al., 2006; Hirsch et al., 2006; Mikaloff Fletcher et al., 2007; Steinkamp, 2011; Lam et al., 2011; Lettmann et al., 2012; Martinez-Camara et al., 2014; Louca et al., 2016). We mention that most existing studies — including those investigating metabolite fluxes in anoxic water columns or sediments (Berg et al., 1998; Lam et al., 2011; Lettmann et al., 2012; Louca et al., 2016) assumed that $C$ was at steady state even when fluxes were estimated at multiple time points, however this assumption may be needlessly and overly restrictive. To reduce spurious oscillations in the estimated $R$ (a common ILTM artifact), excessively high estimates of $R$ that only marginally improve the agreement with the data are penalized, a procedure known as Tikhonov regularization (Björck, 1996; Hansen, 2000; Lettmann et al., 2012). Specifically, for any given metabolite, the vector containing all values of $R$ on the fitting grid (denoted $\mathbf{R}$ ) is estimated by minimizing the expression:

$$
E(\mathbf{R})=\left\|\mathbf{C}^{o}+\mathbb{T} \cdot \mathbf{R}-\mathbf{C}\right\|^{2}+\|\lambda \mathbf{R}\|^{2}
$$

Here, $\mathbf{C}$ is a vector listing measured concentrations at arbitrary spacetime points, $\mathbf{C}^{o}$ is a pre-calculated vector listing concentrations predicted in the absence of any net production (i.e., when $R=0$ and accounting for initial and boundary conditions, Supplemental Fig. S.7), $\|\cdot\|^{2}$ denotes the squared norm of a vector (i.e., the sum of squares of all its components) and $E(\mathbf{R})$ denotes the function to be minimized by appropriate choice of $\mathbf{R}$. The matrix $\mathbb{T}$ maps net production rates on the fitting grid to concentrations on the same spacetime points as the data, and is pre-calculated using the differential equation (6). The first $\|\cdot\|^{2}$ term in Eq. (7) corresponds to the deviation of the predicted concentrations from the data, while the second $\|\cdot\|^{2}$ term corresponds to the overall magnitude of the estimated net production rates. The "regularization factor" $\lambda$ modulates the penalization of spurious rate estimates, balanced against achieving a better fit to the data, and is chosen adaptively and separately for each metabolite depending on the data using a crossvalidation algorithm (Golub et al., 1979). Hence, for a chosen $\lambda$, the task of estimating net production rates based on concentration data translates to an optimization problem, which can be solved numerically using linear algebra software (Supplement S.4). Because all data points $\mathbf{C}$ are used concurrently to fit the full spatiotemporal rate profile $\mathbf{R}$, this method is more robust against measurement errors than previous methods that only use data from a single time point at a time (Berg et al., 1998; Lam et al., 2011; Lettmann et al., 2012; Louca et al., 2016).

We emphasize that the resolution and placement of the fitting grid must be chosen carefully to avoid the risk of overfitting. Indeed, the number of spacetime points on the fitting grid dictates the number of fitted free parameters, and hence the fitting grid must be much coarser than the concentration data $\mathbf{C}$. At the same time, the fitting grid should capture the major variations in $R$ over space and time, as indicated in the concentration data. Hence, the fitting grid should be densest in those spacetime regions where $R$ is suspected to vary most and where, ideally, concentration measurements are also densest. The latter constraint 
underscores the importance of carefully choosing the times and depths targeted by oceanographic surveys. In practice, the fitting grid may need to be revised through trial and error and using expert knowledge of the system, for example where substantial oscillations in the estimated rates are obviously spurious. A common and useful difference between spurious and true variations in the estimated $R$ is that the former tend to be much more sensitive to small variations in the fitting grid.

\subsection{Metabolite fluxes in Cariaco Basin}

We used the above ILTM approach to estimate net in situ production rates of several important dissolved metabolites in the Cariaco Basin sub-euphotic water column, using concentration time series spanning depths 150-900 m and years 2001-2014 (Fig. 2A-F). In addition to production rate estimates, we also estimated vertical metabolite flux rates from the bottom (depths $>900 \mathrm{~m}$ ) and from the overlying waters (depths $<150 \mathrm{~m})$ into the sub-euphotic zone and into the redoxcline. Estimated net metabolite production rates, interpolated between grid points, are shown in Fig. 3. The agreement between the measured metabolite concentrations and those predicted based on the estimated net production rates was generally good, with a fraction of explained variance $\left(r^{2}\right)$ between 0.878 and 0.973 depending on the metabolite (Fig. 2). The main features not captured by the fitted models are rapid fluctuations constrained within small depth intervals, potentially originating from occasional lateral water intrusions (Scranton et al., 2014; Muller-Karger et al., 2019), as well as seasonally driven variations in oxygen and nitrate concentrations (Fig. 2). In contrast, the fitted models accurately capture major decadal trends, most prominently seen in the sulfide and methane profiles (Figs. $2 \mathrm{C}, \mathrm{E})$. The inability of the fitted models to capture rapid transient small-scale fluctuations stems from two fundamentally information-theoretical limitations: First, the spatiotemporal resolution of the available data imposes a bound on the resolution of the fitting grid on which $R$ can be independently estimated, and greater grid resolutions would substantially increase the risk of overfitting. Second, the estimation of $R$ mathematically corresponds to an inversion (specifically, a deconvolution) of the diffusion process, and hence tends to amplify high-frequency noise in the data; the amplified noise manifests as spurious rapid oscillations in the estimated rates that are hard to distinguish from real fluctuations (Steinkamp, 2011; Lettmann et al., 2012). The temporal resolution of our estimates is thus constrained by the time scales associated with diffusive mixing in Cariaco Basin which, based on the typical travel times of diffusing particles between the bottom boundary and the redoxcline, are in the order of $\sim 2.4$ years (Supplement S.2). Thus, estimated metabolic rates at any time point should be seen as local temporal averages over those time scales.

Our estimates clearly indicate a production of nitrate near the top (depths $150 \mathrm{~m}-250 \mathrm{~m}$ ) and its consumption in the immediately underlying layers (250-300 m, Figs. 3A,B). The weak apparent production of oxygen estimated near the top is likely due to advective (e.g., lateral) transport and/or estimation error, rather than actual in situ production at those depths. When integrated across all depths, estimated in situ nitrate production near the top almost exactly matches the in situ consumption of nitrate immediately below, whereas most of the oxygen consumed in the redoxcline originates from much shallower depths $(<150 \mathrm{~m}$, summaries in Table 1). These observations are not surprising, since the main sources of oxygen are the atmosphere and primary production at the surface, while nitrate is likely largely produced by nitrifiers throughout the 
oxycline wherever ammonium is available and used at depth mostly as an electron acceptor for respiration (Scranton et al., 2014; Cernadas-Martín et al., 2017; Taylor et al., 2018). Using negative values of $R$ as an estimate of gross consumption rates, and integrating over all depths, we estimate a gross oxygen consumption of $\sim 13 \mathrm{mmol} \cdot \mathrm{m}^{-2} \cdot \mathrm{d}^{-1}$ and a gross nitrate consumption of $\sim 2.6 \mathrm{mmol} \cdot \mathrm{m}^{-2} \cdot \mathrm{d}^{-1}$ on average, indicating that oxygen is a more important terminal electron acceptor in this system than nitrate. Major reductants such as hydrogen sulfide, ammonium and methane diffuse upwards from the bottom layers into the redoxcline where they are largely consumed (Figs. 3C,D,E). The biologically driven flux of electrons from upward diffusing electron donors onto downward diffusing electron acceptors, fuels chemolithoautotrophic microbial activity within the redoxcline (Figs. 4A) and sustains high prokaryotic cell densities (Fig. 4D; Taylor et al., 2006). When integrated (summed) over all considered depths, we estimate an average consumption rate of $11 \mathrm{mmol} \cdot \mathrm{m}^{-2} \cdot \mathrm{d}^{-1}$ for sulfide, $4.7 \mathrm{mmol} \cdot \mathrm{m}^{-2} \cdot \mathrm{d}^{-1}$ for ammonium and $3.3 \mathrm{mmol} \cdot \mathrm{m}^{-2} \cdot \mathrm{d}^{-1}$ for methane, where all area-specific quantities reported here and below are normalized to the basin area at depth $150 \mathrm{~m}$ for ease of comparison. The bulk of sulfide, ammonium and methane consumption was found to occur within the redoxcline (overviews in Table 1 and Supplemental Tables S.1 and S.2).

Our estimated sulfide and methane consumption rates are much greater than those estimated by previous studies $\left(\sim 0.1-1.3 \mathrm{mmol} \cdot \mathrm{m}^{-2} \cdot \mathrm{d}^{-1}\right.$ for sulfide; Taylor et al., 2001; Li et al., 2012b; Taylor et al., 2018 or $\sim 0.04-0.07 \mathrm{mmol} \cdot \mathrm{m}^{-2} \cdot \mathrm{d}^{-1}$ for methane; Ward et al., 1987; Li et al., 2012b), especially when considering that these previous values would be further reduced after accounting for the smaller basin area at the depths where they were measured (compared to $150 \mathrm{~m}$ ). This disagreement can be largely explained by the lower diffusivities assumed or estimated in these studies; these studies do acknowledge the great uncertainty in their diffusivity estimates. Our work thus provides a possible explanation for a heavily discussed apparent "conundrum", whereby sulfide and other electron donor fluxes estimated for Cariaco Basin appeared too low to explain measured dark carbon assimilation (DCA) rates (Taylor et al., 2001; Li et al., 2012b; Jost, 2012; Li et al., 2012a). For example, sulfide fluxes into the redoxcline estimated by Li et al. (2012b) are about 50 times lower than ours; assuming a stoichiometric ratio of $1 \mathrm{~mol} \mathrm{C}$ fixed per $\mathrm{mol} \mathrm{H}_{2} \mathrm{~S}$ oxidized, Li et al. estimated that only $0.2-4.2 \%$ of the depth-integrated DCA rate could be explained by sulfide fluxes or, alternatively, that 212 mol-C had to be assimilated per mol- $\mathrm{H}_{2} \mathrm{~S}$ oxidized on average. According to our sulfide consumption rate estimate $\left(11 \mathrm{mmol} \cdot \mathrm{m}^{-2} \cdot \mathrm{d}^{-1}\right.$ on average $)$ and depth-integrated DCA rates $\left(31.6 \mathrm{mmol}-\mathrm{C} \cdot \mathrm{m}^{-2} \cdot \mathrm{d}^{-1}\right.$ on average, Fig. 4A and Taylor et al., 2018), and assuming that sulfide (eventually oxidized to sulfate) is the major source of energy for primary production in the redoxcline (Li et al., 2012b; Taylor et al., 2018), we estimate an average system-wide yield factor of $\sim 2.9 \mathrm{~mol} \mathrm{C}$ fixed per mol sulfide oxidized. This estimate is still higher than yield factors previously obtained from laboratory cultures of sulfide oxidizers $(0.14-0.42$ mol C fixed per mol $\mathrm{H}_{2} \mathrm{~S}$; Tuttle and Jannasch, 1979; Kelly, 1990). One explanation may be that energy limitation in Cariaco Basin's stagnant sub-oxic waters selects for oligotrophic microorganisms, capable of more efficient substrate use than laboratory isolates. Indeed, the energy requirements and efficiencies of various carbon fixation pathways vary widely, depending on the organisms and ecological niches filled (BarEven et al., 2011; Berg, 2011; Klatt and Polerecky, 2015). If we follow the thermodynamic arguments by Li et al. (2012b), then sulfide-oxidizing chemolithoautotrophic communities in Cariaco Basin may be capable of fixing up to 6.6 mol-C per mol- $\mathrm{H}_{2} \mathrm{~S}$, well above our estimated yield factor. Further, since we ignored the 
contribution of other electron donors such as ammonium and methane, our estimated yield factor is probably itself an overestimate of the true sulfide-specific yield factor. We also emphasize that this yield factor is an empirical average property of the entire microbial system during the considered time period, and may vary over depth and time depending on environmental conditions and biological interactions. The limited temporal resolution of ILTM-estimated sulfide consumption rates, compared to the rapidly fluctuating measured DCA rates (Fig. 4A), currently hinders a meaningful assessment of the variability of this yield factor.

Most of the sulfide, ammonium and methane input into the system (i.e., via diffusion or in situ production) can be attributed to diffusion from the bottom boundary (91\%, 95\% and 97\%, respectively), potentially produced near or in the underlying sediments. Our estimates suggest that some hydrogen sulfide is also produced within the water column (depths $\sim 600-900 \mathrm{~m}$ ), consistent with the previous detection of sulfatereducing bacteria in sinking particles at anoxic depths (Suter et al., 2018), although some of the sulfide sources may actually be sulfide diffusing out of the sediments on the basin's side walls. The contribution of in situ sulfide sources to overall sulfide fluxes into the redoxcline is relatively small $(\sim 10 \%)$ and has decreased in the latter years, based on the estimated ratio of in situ produced versus in situ consumed sulfide. A relatively minor contribution of in situ sulfide sources is consistent with previous hypotheses (Scranton et al., 1987; Ho et al., 2004). We also found that the majority of phosphate input (gross in situ production + influx across the boundaries) is due to diffusion from the bottom boundary ( $\sim 65 \%)$. This phosphate influx from the bottom may partly originate from the remineralization of organic matter in the sediments. Indeed, the estimated ratio of time-averaged ammonium influx vs. phosphate influx from the bottom is $\sim 17: 1$, closely resembling typical stoichiometric ratios of particulate organic matter in coastal marine ecosystems (17:1 on average; Sterner et al., 2008).

Below the oxic zone, nitrate is presumably used as a terminal electron acceptor by heterotrophic and/or lithotrophic prokaryotes (Scranton et al., 2014; Rodriguez-Mora et al., 2015), fueling complete denitrification to $\mathrm{N}_{2}$ (Montes et al., 2013) and/or partial denitrification to intermediates such as nitrite. Since nitrite rarely accumulates below $150 \mathrm{~m}$ (Supplemental Fig. S.10), any produced nitrite appears to be re-oxidized to nitrate, further reduced by denitrifiers, or used to anaerobically oxidize ammonium (anammox). The occurrence of denitrification and anammox would be consistent with the reduced ratios of dissolved inorganic nitrogen to phosphorus (N/P) observed in the redoxcline (Muller-Karger et al., 2019), the detection of bacteria capable of various denitrification steps and anammox (Rodriguez-Mora et al., 2015; Cernadas-Martín et al., 2017; Taylor et al., 2018), and similar observations in other oxygen-depleted water columns (Lam and Kuypers, 2011; Lam et al., 2011; Ulloa et al., 2012). Given that sulfide oxidation spatially overlaps substantially with nitrate consumption (Fig. 4C), it is probable that nitrate is at least partly used as a terminal electron acceptor for the oxidation of various sulfur compounds, a process observed in other oxygen-depleted regions of the ocean (Canfield et al., 2010; Schunck et al., 2013; Louca et al., 2016; Rogge et al., 2017). Indeed, the Gammaproteobacterial clades BS-GSO2 and SUP05, members of which are frequently implicated in sulfide oxidation and denitrification in oxygen-poor marine systems (Lavik et al., 2009; Walsh et al., 2009; Fuchsman et al., 2012; Glaubitz et al., 2013; Shah et al., 2017; Rogge et al., 2017), have been observed at high relative abundances in the Cariaco Basin redoxcline (Rodriguez-Mora et al., 2015; Taylor et al., 2018; 
Suter et al., 2018).

Our estimates reveal a weak but relatively steady consumption of phosphate $\left(0.30 \mathrm{mmol} \cdot \mathrm{m}^{-2} \cdot \mathrm{d}^{-1}\right.$ on average) between depths $\sim 150-250 \mathrm{~m}$, and a similarly steady production of phosphate $\left(0.17 \mathrm{mmol} \cdot \mathrm{m}^{-2} \cdot \mathrm{d}^{-1}\right.$ on average) between depths $\sim 250-350 \mathrm{~m}$ (Fig. 3F). This spatially adjacent consumption and production of phosphate leads to the appearance of a subtle phosphate minimum and maximum around the upper and lower half of the redoxcline, respectively. This pattern has been previously partly attributed to a "metal redox shuttle", whereby phosphate is scavenged during ferrous and manganese oxide formation in the redoxcline and subsequently redissolved at depth (Dellwig et al., 2010; McParland et al., 2015; Muller-Karger et al., 2019). Prokaryotic chemolithoautotrophic activity may also partly drive phosphate consumption within the redoxcline, as suggested by McParland et al. (2015) and, in turn, the phosphate production seen immediately below may be due to the remineralization of sinking biomass. The relative importance of such a "biomass shuttle" to the phosphate pool has so far been unclear. Assuming an atomic C:P ratio of 41 for prokaryotic cells (Vrede et al., 2002), and an average dark carbon assimilation rate of $5.25 \mathrm{mmol}-\mathrm{C} \cdot \mathrm{m}^{-2} \cdot \mathrm{d}^{-1}$ between depths 150-250 m (Fig. 4A), one would predict a chemolithoautotrophy-driven phosphate consumption rate of $0.13 \mathrm{mmol} \cdot \mathrm{m}^{-2} \cdot \mathrm{d}^{-1}$. This prediction is about half of the estimated phosphate consumption rate within that depth range. Hence, a biomass shuttle could only partly explain the phosphate sink and source within the redoxcline, further emphasizing the importance of a putative metal redox shuttle.

We find that the consumption of hydrogen sulfide, methane and, to a lesser extent, ammonium and phosphate has gradually shifted towards shallower depths, and this shift is particularly apparent when comparing times before the year 2010 and afterwards. We also estimate that in situ sulfide production at depth substantially decreased over time (Fig. 3C). After 2009, the estimated amount of sulfide produced in situ became negligible $(<1 \%)$ compared to sulfide diffusing from the bottom (summaries in Supplemental Table S.1). Concurrently, sulfide concentrations near the bottom ( $~ 1300 \mathrm{~m}$ depth) have increased steadily over time (Supplemental Fig. S.11), potentially due to increased production in the underlying sediments, leading to higher diffusive fluxes across the bottom boundary $\left(\sim 10 \mathrm{mmol} \cdot \mathrm{m}^{-2} \cdot \mathrm{d}^{-1}\right.$ on average before 2010 and $\sim 16 \mathrm{mmol} \cdot \mathrm{m}^{-2} \cdot \mathrm{d}^{-1}$ afterwards, Supplemental Fig. S.12). This might explain why, despite a decrease of in situ sulfide production at depth, net sulfide fluxes into the redoxcline increased $\left(\sim 7.8 \mathrm{mmol} \cdot \mathrm{m}^{-2} \cdot \mathrm{d}^{-1}\right.$ on average before 2010 and $\sim 9.7 \mathrm{mmol} \cdot \mathrm{m}^{-2} \cdot \mathrm{d}^{-1}$ afterwards). Interestingly, the upward shift of the redoxcline and the drop of in situ sulfide production coincide with major shifts in the composition of the sulfur oxidizing community after 2009 (Taylor et al., 2018). Whether the above changes in nutrient fluxes actually affected, and/or were affected by, changes in the redoxcline-inhabiting community remains unclear.

Three words of caution are warranted. First, due to the limited spatial resolution of our data (and thus, our rate estimates) it is possible that the sinks and sources of metabolites are confined to narrower depth intervals than estimated. Consequently, putatively coupled electron donors (such as sulfide) and electron acceptors (such as oxygen or nitrate), seemingly consumed within the same zone, may in reality be consumed within distinct zones and may only be indirectly coupled through redox shuttles such as manganese and iron (Taylor et al., 2001; Percy et al., 2008). Second, with the data at hand, at each location we can a priori only estimate the local net production rate $R$ (gross production minus gross consumption rate), but not the gross 
production and gross consumption rates separately. It is in principle possible that in some locations some metabolites are both produced and consumed concurrently by separate processes, as observed for sulfate and sulfide in other marine anoxic systems (Canfield et al., 2010). Third, the fact that our estimated rate profiles represent locally averaged net rates implies that, a metabolite produced and consumed in distinct zones but nevertheless in close proximity, may be subject to higher turnover rates than can be inferred from our rate profiles. For example, it is possible that nitrate produced by nitrification is rapidly consumed by denitrification in close proximity immediately below (Cernadas-Martín et al., 2017), and that we thus underestimated nitrate turnover rates in the redoxcline.

\subsection{Conclusions}

We have described a computational approach for estimating vertical fluxes and in situ consumption/production rates of dissolved chemical compounds over space and time, via inverse transport modeling. Our approach builds upon established mathematical concepts and has been optimized for water columns or sediments with essentially 1-dimensional geochemical structure, and for which chemical concentrations have been measured at arbitrary spacetime points. We emphasize that despite the apparent simplicity of our models for Cariaco Basin, which assume that eddy diffusion is the dominant mode of salt and metabolite transport in the considered depth interval, our models manage to reproduce the salinity and metabolite concentration data very well ( $r^{2}=0.982$ for salinity, $r^{2}=0.878-0.973$ for metabolites).

We reconstructed vertical fluxes and in situ consumption/production rates of several biologically important metabolites in the Cariaco Basin sub-euphotic water column over the course of 14 years. This allowed us to assess the relative importance of in situ production in the water column versus supply from (or near) the underlying sediments for various reductants fueling microbial productivity in the redoxcline. By independently estimating the diffusivity in Cariaco Basin over depth and time, rather than relying on parameter values from other marine systems, we further constrained an important source of uncertainty in previous flux estimates (Ho et al., 2004; Li et al., 2012b; Samodurov et al., 2013; Taylor et al., 2018). This revealed that fluxes of various electron donors and acceptors, such as hydrogen sulfide and methane, into the redoxcline are about two orders of magnitude greater than previously estimated (Taylor et al., 2001; Li et al., 2012b; Taylor et al., 2018). Our work thus provides a possible resolution to the long unexplained apparent mismatch between electron donor fluxes and dark carbon assimilation rates in Cariaco Basin (Li et al., 2012b; Jost, 2012; Li et al., 2012a). We also estimated that chemolithoautotrophic activity and remineralization of biomass within the redoxcline only partly explains the phosphate minimum and maximum observed within the redoxcline, thus providing evidence for the existence of an alternative phosphate shuttle. Finally, our work demonstrates that, using appropriate mathematical tools, a wealth of seemingly convoluted information on microbial activity can be extracted from standard chemical concentration time series. 


\section{Methods}

\subsection{Cariaco data}

Chemical and physical data from Cariaco station A (coordinates $10.5^{\circ} \mathrm{N}, 64.66^{\circ} \mathrm{W}$ ) were downloaded on April 28, 2018 from the Cariaco Basin time series project website (http://www . imars . usf . edu/cariaco) for station CARIACO. Additional sources of CARIACO chemical data are the NOAA's National Centers for Environmental Information (NCEI), the Ocean Carbon Data System, the US Biological and Chemical Oceanography Data Management Office (BCO-DMO) and the NASA SeaBASS database. Data collection methods have been described previously (Thunell et al., 2000; Li et al., 2008; Scranton et al., 2014; MullerKarger et al., 2019). Additional hydrogen sulfide concentration data, recently published by Muller-Karger et al. (2019), were obtained directly from the authors. The lateral area of the eastern basin (within which station CARIACO is located) at various discrete depths was taken from Samodurov et al. (2013, Table 1), and was linearly interpolated between those depths (Supplemental Fig. S.1).

Inverse linear transport modeling (ILTM) was used to estimate net production rates ( $R$ in Eq. 6) of oxygen, nitrate, hydrogen sulfide, ammonium, methane and phosphate (dissolved pools). These compounds (referred to here as "metabolites") were chosen due to their biological importance within the considered depth interval, their relatively good sampling resolution and spatiotemporal coverage, and the fact that their transport across depth can be largely described by eddy diffusion. Nitrite was not included in ILTM because nitrite rarely accumulates to significant levels (Supplemental Fig. S.10); hence, estimated net production rates would be almost zero and dominated by errors despite potentially intense cryptic nitrite fluxes (e.g., as an intermediate of nitrification or denitrification).

\subsection{Estimating diffusivity in Cariaco Basin}

Salinity and temperature profiles were LOESS-smoothened at degree 1 and a span of $10 \%$ to reduce noise. Salinity, temperature and pressure profiles were used to calculate the buoyancy frequency $(N)$ at each depth and time point, using the R package oce (Kelley, 2014). To reduce noise in the buoyancy frequency stemming from the numerical differentiation of noisy data, the buoyancy frequency was smoothened using a Savitzky-Golay filter of degree 2 along the time axis (Savitzky and Golay, 1964). For any given choice of the parameters $\alpha$ and $p$ (Eq. 1), we simulated the salinity profile over depth and time by solving the differential equation (2), using the pdepe function in $\operatorname{MATLAB}^{\circledR}$. The initial profile was set to the measured salinity profile at the first simulation time point (Jan. 1, 2001). Boundary conditions at the top $(150 \mathrm{~m})$ and bottom boundary $(900 \mathrm{~m}$ ) were of Dirichlet type, with the imposed value at each time point and each boundary being the current measured salinity at the boundary's depth. Salinities between data points were bilinearly interpolated wherever needed for the initial condition and boundary conditions.

We did not account for lateral intrusions of denser, oxygenated water from outside, which are known to occur occasionally in Cariaco Basin (Scranton et al., 2014; Taylor et al., 2018). Salinity and temperature 
profiles during the time period and depth range considered here do not show obvious signs of foreign water intrusions (Supplemental Figs. S.2A,B). Similarly, oxygen concentration profiles show only weak signs of potential intrusions of oxygenated water at depth (Fig. 2A). It is in principle possible that intrusion events, the subsequent re-equilibration of density structure and the consumption of introduced oxidants all occur at much shorter time scales than resolved by the monthly time series. However, the good agreement of the fitted diffusivity models with the salinity data $\left(r^{2}=0.982\right.$, Supplemental Fig. S.3) and the metabolite concentration data $\left(r^{2}=0.878-0.973\right)$ further suggests that lateral water intrusions had little effect on the salt and metabolite budgets within the considered spatiotemporal domain.

The predicted salinity profile $\hat{S}$ was compared to the measured salinity data $(S)$ by means of the fraction of explained variance $\left(r^{2}\right)$, calculated as:

$$
r^{2}=1-\frac{1}{V \cdot n} \sum_{i=1}^{n}\left(\hat{S}_{i}-S_{i}\right)^{2},
$$

where $i$ iterates over all available salinity data points $(n=111,920), \hat{S}_{i}$ is the salinity predicted for the same spacetime point as $S_{i}$ and $V$ is the sample variance of the measured salinities $S_{i}$. The power law parameters $\alpha$ and $p$ were gradually fitted until $r^{2}$ reached a maximum, using the "interior-point" optimization algorithm encoded by the function fmincon in MATLAB ${ }^{\circledR}$. To avoid non-global local optima, we repeated the fitting 200 times, each time with randomly chosen initial values for $\alpha$ and $p$. The distribution of fitted parameters, as a function of the maximized $r^{2}$, is shown in Supplemental Fig. S.13. The parameter set corresponding to the highest $r^{2}$ was taken as the final estimate. The same approach was also used to fit the Munk-Anderson diffusivity model (Eq. 3), as well as the combined power-law + Munk-Anderson model (sum of Eqs. 1 and 3). For details on the "anchored" diffusivity estimate (Eq. 4), performed here solely for sanity checking purposes, see Supplement S.1. For the subsequent ILTM analysis, we used the diffusivity obtained from the fitted power-law model.

\subsection{Inverse linear transport modeling}

Mathematical background and computational details on our ILTM approach are provided in Supplement S.4. Briefly, the differential equation (6) was used to calculate a linear mapping (represented as a matrix $\mathbb{T}$, see Eq. 7) between any given net production rates (on a finite grid of spacetime points) and the corresponding predicted volumetric concentration profiles (on the same spacetime points as the concentrations measurements). The spatiotemporal grid on which $R$ was estimated ("fitting grid") was chosen separately for each metabolite to account for differences in sampling resolution and spatiotemporal variability of metabolite concentrations, and such that its size was substantially lower than the number of available data points (overview in Supplemental Fig. S.6 and Supplemental Table S.3). In all cases, the number of considered data points was more than 10 times the size of the fitting grid.

Prior to any prediction, the net production rates on the fitting grid were interpolated onto a high-resolution grid ("refined grid") using an interpolation matrix II, which maps rates on the fitting grid to rates on the 
refined grid. Because our numerical differential equation solver only returns solutions on a rectangular spatiotemporal grid ("prediction grid"), an additional interpolation is performed from the prediction grid onto the spacetime points of the data (using a suitable matrix $\mathbb{P}$ ). Hence, $\mathbb{T}$ is composed of 3 matrices, $\mathbb{T}=\mathbb{P} \cdot \mathbb{G} \cdot \mathbb{I}$, where $\mathbb{G}$ encodes the "Green's function" (sometimes called "fundamental solution") of the differential equation (Duffy, 2001). Each row in the matrix $\mathbb{G}$ corresponds to the solution of the differential equation (6) evaluated at a specific point on the prediction grid, if the net production rate was zero in all but a single point on the refined grid. The resolutions of the refined grid and the prediction grid were chosen sufficiently high to ensure a high accuracy of the solutions of the differential equation. The estimation of net production rates on the fitting grid can be formulated as a least-squares optimization problem (minimizing the expression in Eq. 7), which we solved using linear algebra routines in MATLAB ${ }^{\circledR}$ (MATLAB, 2010). For each metabolite, the fraction of variance explained by the predicted concentrations $\left(r^{2}\right)$ was calculated as described above for the salinity model.

\subsection{Estimation of depth-integrated fluxes and area-specific quantities}

In all cases, depth-integration of rates and concentrations took into account the variation of the lateral (crosssectional) basin area with depth (Supplemental Fig. S.1), and all depth-integrated quantities (e.g., production rates) and area-specific quantities (e.g., fluxes through the top and bottom boundaries, or fluxes into the redoxcline) are normalized with respect to the basin area at depth $150 \mathrm{~m}$. For example, if $R(t, z)$ is the estimated net production rate of some metabolite, then its depth-integrated value within some depth-interval $\left[z_{1}, z_{2}\right]$, averaged over some time interval $\left[t_{1}, t_{2}\right]$, was defined as:

$$
\bar{R}:=\frac{1}{t_{2}-t_{1}} \int_{t_{1}}^{t_{2}} d t \int_{z_{1}}^{z_{2}} d z R(t, z) \frac{A(z)}{A\left(z_{o}\right)}
$$

where $A(z)$ is the lateral basin area and $z_{o}=150 \mathrm{~m}$. Thus, in this example, $\bar{R}$ is the hypothetical area-specific vertical flux one would observe at depth $z_{o}$ if the total number of metabolite molecules produced between depths $z_{1}$ and $z_{2}$ (integrated over all latitudes/longitudes) was equal to the number of molecules vertically transported past depth $z_{o}$. The depth $z_{o}=150 \mathrm{~m}$ was chosen as reference because it is the approximate maximum depth at which Cariaco Basin connects to the ocean, thus marking the Basin's "upper boundary", although any other depth could have been used instead.

Net metabolite flux rates across the top $(150 \mathrm{~m})$ and bottom boundary $(900 \mathrm{~m})$ were estimated from the local metabolite concentration gradients and the local diffusivities. Gross influx rates and gross outflux rates through each boundary were then estimated by using the positive or negative part of the net flux rates, as appropriate. Net in situ production rates were estimated via ILTM fitting, as described above. Gross production rates or gross consumption rates were then estimated by taking the positive or negative part of the net production rates, as appropriate. Note that this approach may underestimate actual production and consumption rates, if these occur concurrently at the same depth, since ILTM can a priori only reveal net rates. Estimated in situ gross production and gross consumption rates were depth-integrated using the trapezoid rule. A metabolite's mean total input rate $\left(R_{i}\right.$, in $\left.\mathrm{mmol} \cdot \mathrm{m}^{-2} \cdot \mathrm{d}^{-1}\right)$ was defined as the sum of the time- 
averaged depth-integrated estimated gross production rate plus its time-averaged gross influx rates at the top and bottom boundaries (all normalized to the basin area at depth $150 \mathrm{~m}$ ). Similarly, a metabolite's mean total output rate $\left(R_{o}\right)$ was defined as the sum of the time-averaged depth-integrated estimated gross consumption rate plus its time-averaged gross outflux rates at the top and bottom boundaries. A metabolite's total content $\left(X\right.$, in $\mathrm{mol} \cdot \mathrm{m}^{-2}$ ) was calculated by integrating the metabolite's measured concentration over the entire depth interval while accounting for the variable lateral (cross-sectional) basin area, and subsequently averaged over time. The mean residence time of a metabolite in the considered water column (depths 150-900 m) was estimated from the non-time-averaged total input and output rates $\left(R_{i}(t)\right.$ and $\left.R_{o}(t)\right)$ and the non-timeaveraged total content $(X(t)$ ), based on a non-steady-state box model (see Supplement S.3). We mention that, in the case of steady state the mean residence time predicted by the box model would be $X / R_{o}$; this simplified formula was used previously by Li et al. (2012b) under the implicit assumption of steady state. All estimates are listed in Table 1 and Supplemental Tables S.1 and S.2.

\section{Data Availability}

All raw data used in this article have been published previously (Scranton et al., 2014; Muller-Karger et al., 2019) and are publicly available at the Cariaco Basin Time Series project website (http://www. imars . usf.edu/cariaco).

\section{Code availability}

Our MATLAB ${ }^{\circledR}$ code for estimating diffusivity based on salinity profiles and for estimating metabolite fluxes via ILTM is available online at: www.loucalab.com/archive/CariacoMetabolic

\section{Competing financial interests}

The authors declare that they have no competing interests.

\section{References}

Armi, L. (1979) Effects of variations in eddy diffusivity on property distributions in the oceans. Journal of Marine Research 37: 515-529.

Bar-Even, A., Noor, E., and Milo, R. (2011) A survey of carbon fixation pathways through a quantitative lens. Journal of Experimental Botany 63: 2325-2342.

Berg, I.A. (2011) Ecological aspects of distribution of different autotrophic CO2 fixation pathways. Applied and Environmental Microbiology 77: 1925-1936. 
Berg, P., Risgaard-Petersen, N., and Rysgaard, S. (1998) Interpretation of measured concentration profiles in sediment pore water. Limnology and Oceanography 43: 1500-1510.

Björck, A. (1996) Numerical Methods for Least Squares Problems. Society for Industrial and Applied Mathematics.

Breitburg, D., Levin, L.A., Oschlies, A., Grégoire, M., Chavez, F.P., Conley, D.J., et al. (2018) Declining oxygen in the global ocean and coastal waters. Science 359: eaam7240.

Canfield, D.E., Stewart, F.J., Thamdrup, B., De Brabandere, L., Dalsgaard, T., Delong, E.F., et al. (2010) A cryptic sulfur cycle in oxygen-minimum-zone waters off the Chilean coast. Science 330: 1375-1378.

Cernadas-Martín, S., Suter, E.A., Scranton, M.I., Astor, Y., and Taylor, G.T. (2017) Aerobic and anaerobic ammonium oxidizers in the Cariaco Basin: distributions of major taxa and nitrogen species across the redoxcline. Aquatic Microbial Ecology 79: 31-48.

Dellwig, O., Leipe, T., März, C., Glockzin, M., Pollehne, F., Schnetger, B., et al. (2010) A new particulate $\mathrm{Mn}-\mathrm{Fe}-\mathrm{P}-$ shuttle at the redoxcline of anoxic basins. Geochimica et Cosmochimica Acta 74: 7100-7115.

Duffy, D. (2001) Green's Functions with Applications. Applied Mathematics. Taylor \& Francis.

Fennel, K. and Boss, E. (2003) Subsurface maxima of phytoplankton and chlorophyll: Steady-state solutions from a simple model. Limnology and Oceanography 48: 1521-1534.

Fuchsman, C., Murray, J., and Staley, J. (2012) Stimulation of autotrophic denitrification by intrusions of the Bosporus plume into the anoxic Black Sea. Frontiers in Microbiology 3: 257.

Gade, H.G. (1970) Hydrographic investigations in the Oslofjord: A study of water circulation and exchange processes, volume 1. University of Bergen.

Gargett, A. (1984) Vertical eddy diffusivity in the ocean interior. Journal of Marine Research 42: 359-393.

Gargett, A.E. and Holloway, G. (1984) Dissipation and diffusion by internal wave breaking. Journal of Marine Research 42: 15-27.

Glaubitz, S., Kießlich, K., Meeske, C., Labrenz, M., and Jürgens, K. (2013) SUP05 dominates the Gammaproteobacterial sulfur oxidizer assemblages in pelagic redoxclines of the central Baltic and Black Seas. Applied and Environmental Microbiology 79: 2767-2776.

Golub, G.H., Heath, M., and Wahba, G. (1979) Generalized cross-validation as a method for choosing a good ridge parameter. Technometrics 21: 215-223.

Goyet, C., Millero, F.J., O’Sullivan, D.W., Eischeid, G., McCue, S.J., and Bellerby, R.G.J. (1998) Temporal variations of pCO2 in surface seawater of the Arabian Sea in 1995. Deep Sea Research Part I: Oceanographic Research Papers 45: 609-623. 
Gregg, M.C. (1977) Variations in the intensity of small-scale mixing in the main thermocline. Journal of Physical Oceanography 7: 436-454.

Gregg, M.C., D’Asaro, E.A., Shay, T.J., and Larson, N. (1986) Observations of persistent mixing and nearinertial internal waves. Journal of Physical Oceanography 16: 856-885.

Hansen, P.C. (2000) The L-curve and its use in the numerical treatment of inverse problems. In J. P (ed.) Computational Inverse Problems in Electrocardiology, Advances in Computational Bioengineering, pp. 119-142. WIT Press.

Hirsch, A.I., Michalak, A.M., Bruhwiler, L.M., Peters, W., Dlugokencky, E.J., and Tans, P.P. (2006) Inverse modeling estimates of the global nitrous oxide surface flux from 1998-2001. Global Biogeochemical Cycles 20.

Ho, T.Y., Taylor, G.T., Astor, Y., Varela, R., Müller-Karger, F., and Scranton, M.I. (2004) Vertical and temporal variability of redox zonation in the water column of the Cariaco Basin: implications for organic carbon oxidation pathways. Marine Chemistry 86: 89-104.

Houweling, S., Kaminski, T., Dentener, F., Lelieveld, J., and Heimann, M. (1999) Inverse modeling of methane sources and sinks using the adjoint of a global transport model. Journal of Geophysical Research: Atmospheres (1984-2012) 104: 26137-26160.

Ivanov, L. and Samodurov, A. (2001) The role of lateral fluxes in ventilation of the Black Sea. Journal of Marine Systems 31: 159-174.

James, I. (1977) A model of the annual cycle of temperature in a frontal region of the Celtic Sea. Estuarine and Coastal Marine Science 5: 339-353.

Jost, G. (2012) A comment to "The conundrum between chemoautotrophic production and reductant and oxidant supply: A case study from the Cariaco Basin,"published by Li et al. (2012). Deep Sea Research Part I: Oceanographic Research Papers 70: 103-105.

Kelley, D. (2014) oce: Analysis of oceanographic data. R package version 0.9-13.

Kelly, D. (1990) Energetics of chemolithotrophs‘. In T. Krulwich (ed.) Bacterial Energetics, pp. 479-503. San Diego: Academic Press.

Kideys, A.E. (2002) Fall and rise of the Black Sea ecosystem. Science 297: 1482-1484.

Klatt, J.M. and Polerecky, L. (2015) Assessment of the stoichiometry and efficiency of CO2 fixation coupled to reduced sulfur oxidation. Frontiers in Microbiology 6: 484.

Knowles, I. and Renka, R.J. (2014) Methods for numerical differentiation of noisy data. Electronic Journal of Differential Equations 21: 235-246.

Lam, P., Jensen, M.M., Kock, A., Lettmann, K.A., Plancherel, Y., Lavik, G., et al. (2011) Origin and fate of the secondary nitrite maximum in the Arabian Sea. Biogeosciences 8: 1565-1577. 
Lam, P. and Kuypers, M.M. (2011) Microbial nitrogen cycling processes in oxygen minimum zones. Annual Review of Marine Science 3: 317-345.

Lavik, G., Stuhrmann, T., Bruchert, V., Van der Plas, A., Mohrholz, V., Lam, P., et al. (2009) Detoxification of sulphidic african shelf waters by blooming chemolithotrophs. Nature 457: 581-584.

Lee, H.C., Rosati, A., and Spelman, M.J. (2006) Barotropic tidal mixing effects in a coupled climate model: Oceanic conditions in the Northern Atlantic. Ocean Modelling 11: 464-477.

Leppäranta, M. and Myrberg, K. (2009) Topography and hydrography of the Baltic Sea, pp. 41-88. Berlin, Heidelberg: Springer Berlin Heidelberg.

Lettmann, K.A., Riedinger, N., Ramlau, R., Knab, N., Böttcher, M.E., Khalili, A., et al. (2012) Estimation of biogeochemical rates from concentration profiles: A novel inverse method. Estuarine, Coastal and Shelf Science 100: 26-37.

Lewis, E. and Perkin, R. (1982) Seasonal mixing processes in an arctic fjord system. Journal of Physical Oceanography 12: 74-83.

Li, X., Taylor, G.T., Astor, Y., and Scranton, M.I. (2008) Relationship of sulfur speciation to hydrographic conditions and chemoautotrophic production in the Cariaco Basin. Marine Chemistry 112: 53-64.

Li, X., Taylor, G.T., Astor, Y., Varela, R., and Scranton, M.I. (2012a) Response to comment on "The conundrum between chemoautotrophic production and reductant and oxidant supply: A case study from the Cariaco basin". Deep Sea Research Part I: Oceanographic Research Papers 70: 106-108.

Li, X.N., Taylor, G.T., Astor, Y., Varela, R., and Scranton, M.I. (2012b) The conundrum between chemoautotrophic production and reductant and oxidant supply: A case study from the Cariaco Basin. Deep Sea Research Part I: Oceanographic Research Papers 61: 1-10.

Louca, S., Hawley, A.K., Katsev, S., Torres-Beltran, M., Bhatia, M.P., Kheirandish, S., et al. (2016) Integrating biogeochemistry with multiomic sequence information in a model oxygen minimum zone. Proceedings of the National Academy of Sciences 113: E5925-E5933.

Martinez-Camara, M., Béjar Haro, B., Stohl, A., and Vetterli, M. (2014) A robust method for inverse transport modeling of atmospheric emissions using blind outlier detection. Geoscientific Model Development 7: $2303-2311$.

MATLAB (2010) version 7.10.0 (R2010a). Natick, Massachusetts: The MathWorks Inc.

McParland, E., Benitez-Nelson, C.R., Taylor, G.T., Thunell, R., Rollings, A., and Lorenzoni, L. (2015) Cycling of suspended particulate phosphorus in the redoxcline of the Cariaco Basin. Marine Chemistry 176: $64-74$. 
Mikaloff Fletcher, S.E., Gruber, N., Jacobson, A.R., Doney, S.C., Dutkiewicz, S., Gerber, M., et al. (2006) Inverse estimates of anthropogenic $\mathrm{CO} 2$ uptake, transport, and storage by the ocean. Global Biogeochemical Cycles 20: GB1010.

Mikaloff Fletcher, S.E., Gruber, N., Jacobson, A.R., Gloor, M., Doney, S.C., Dutkiewicz, S., et al. (2007) Inverse estimates of the oceanic sources and sinks of natural $\mathrm{CO} 2$ and the implied oceanic carbon transport. Global Biogeochemical Cycles 21.

Montes, E., Altabet, M., Muller-Karger, F., Scranton, M., Thunell, R., Benitez-Nelson, C., et al. (2013) Biogenic nitrogen gas production at the oxic-anoxic interface in the Cariaco Basin, Venezuela. Biogeosciences 10: $267-279$.

Muller-Karger, F.E., Astor, Y.M., Benitez-Nelson, C.R., Buck, K.N., Fanning, K.A., Lorenzoni, L., et al. (2019) The scientific legacy of the CARIACO ocean time-series program. Annual Review of Marine Science 11: 5.1-5.25.

Munk, W.H. and Anderson, E.R. (1948) Notes on a theory of the thermocline. Journal of Marine Research 7: 276-295.

Olbers, D. and Eden, C. (2013) A global model for the diapycnal diffusivity induced by internal gravity waves. Journal of Physical Oceanography 43: 1759-1779.

Osborn, T.R. (1980) Estimates of the local rate of vertical diffusion from dissipation measurements. Journal of Physical Oceanography 10: 83-89.

Percy, D., Li, X., Taylor, G.T., Astor, Y., and Scranton, M.I. (2008) Controls on iron, manganese and intermediate oxidation state sulfur compounds in the Cariaco Basin. Marine Chemistry 111: 47-62.

Reed, D.C., Algar, C.K., Huber, J.A., and Dick, G.J. (2014) Gene-centric approach to integrating environmental genomics and biogeochemical models. Proceedings of the National Academy of Sciences 111: 1879-1884.

Rodriguez-Mora, M.J., Scranton, M.I., Taylor, G.T., and Chistoserdov, A.Y. (2015) The dynamics of the bacterial diversity in the redox transition and anoxic zones of the Cariaco Basin assessed by parallel tag sequencing. FEMS Microbiology Ecology 91: fiv088.

Rogge, A., Vogts, A., Voss, M., Jürgens, K., Jost, G., and Labrenz, M. (2017) Success of chemolithoautotrophic SUP05 and Sulfurimonas GD17 cells in pelagic Baltic Sea redox zones is facilitated by their lifestyles as K- and r-strategists. Environmental Microbiology 19: 2495-2506.

Samodurov, A.S., Scranton, M.I., Astor, Y., Ivanov, L.I., Chukharev, A.M., Belokopytov, V.N., et al. (2013) Modeling vertical exchange of heat, salt, and other dissolved substances in the Cariaco Basin. Deep Sea Research Part I: Oceanographic Research Papers 71: 61-72. 
Sarmiento, J., Feely, H., Moore, W., Bainbridge, A., and Broecker, W. (1976) The relationship between vertical eddy diffusion and buoyancy gradient in the deep sea. Earth and Planetary Science Letters 32: $357-370$.

Savitzky, A. and Golay, M.J. (1964) Smoothing and differentiation of data by simplified least squares procedures. Analytical chemistry 36: 1627-1639.

Schmidtko, S., Stramma, L., and Visbeck, M. (2017) Decline in global oceanic oxygen content during the past five decades. Nature 542: 335-339.

Schunck, H., Lavik, G., Desai, D.K., Großkopf, T., Kalvelage, T., Löscher, C.R., et al. (2013) Giant hydrogen sulfide plume in the oxygen minimum zone off Peru supports chemolithoautotrophy. PLoS ONE 8: e68661.

Scranton, M.I., Sayles, F.L., Bacon, M.P., and Brewer, P.G. (1987) Temporal changes in the hydrography and chemistry of the Cariaco Trench. Deep Sea Research Part A. Oceanographic Research Papers 34: 945-963.

Scranton, M.I., Taylor, G.T., Thunell, R., Benitez-Nelson, C.R., Muller-Karger, F., Fanning, K., et al. (2014) Interannual and subdecadal variability in the nutrient geochemistry of the Cariaco Basin. Oceanography 27: $148-159$.

Shah, V., Chang, B.X., and Morris, R.M. (2017) Cultivation of a chemoautotroph from the SUP05 clade of marine bacteria that produces nitrite and consumes ammonium. ISME Journal 11: 263-271.

Smethie, W.M. (1980) Estimation of vertical mixing rates in fjords using naturally occurring Radon-222 and salinity as tracers. In Fjord Oceanography, pp. 241-249. Springer.

Steinkamp, K. (2011) Inverse modeling of the sources and sinks of atmospheric CO2: joint constraints from the ocean and atmosphere. Ph.D. thesis, ETH Zurich.

Sterner, R.W., Andersen, T., Elser, J.J., Hessen, D.O., Hood, J.M., McCauley, E., et al. (2008) Scaledependent carbon: nitrogen: phosphorus seston stoichiometry in marine and freshwaters. Limnology and Oceanography 53: 1169-1180.

Suter, E.A., Pachiadaki, M., Taylor, G.T., Astor, Y., and Edgcomb, V.P. (2018) Free-living chemoautotrophic and particle-attached heterotrophic prokaryotes dominate microbial assemblages along a pelagic redox gradient. Environmental Microbiology 20: 693-712.

Svensson, T. (1980) Tracer measurement of mixing in the deep water of a small, stratified sill fjord. In H. Freeland, D. Farmer, and C. Levings (eds.) Fjord Oceanography, volume 4, pp. 233-240. Springer.

Taylor, G., Iabichella-Armas, M., Varela, R., Müller-Karger, F., Lin, X., and Scranton, M. (2006) Microbial ecology of the Cariaco basin's redoxcline: the U.S.-Venezuela Cariaco times series program. In L.N. Neretin (ed.) Past and Present Water Column Anoxia, Nato Science Series: IV: Earth and Environmental Sciences, volume 64, pp. 471-499. Springer Netherlands. 
Taylor, G.T., Iabichella, M., Ho, T.Y., Scranton, M.I., Thunell, R.C., Muller-Karger, F., et al. (2001) Chemoautotrophy in the redox transition zone of the Cariaco Basin: a significant midwater source of organic carbon production. Limnology and Oceanography 46: 148-163.

Taylor, G.T., Suter, E.A., Pachiadaki, M.G., Astor, Y., Edgcomb, V.P., and Scranton, M.I. (2018) Temporal shifts in dominant sulfur-oxidizing chemoautotrophic populations across the Cariaco Basin's redoxcline. Deep Sea Research Part II: Topical Studies in Oceanography 156: 80-96.

Thunell, R.C., Varela, R., Llano, M., Collister, J., Muller-Karger, F., and Bohrer, R. (2000) Organic carbon fluxes, degradation, and accumulation in an anoxic basin: sediment trap results from the Cariaco Basin. Limnology and Oceanography 45: 300-308.

Tuttle, J.H. and Jannasch, H.W. (1979) Microbial dark assimilation of CO2 in the Cariaco Trench. Limnology and Oceanography 24: 746-753.

Ulloa, O., Canfield, D.E., DeLong, E.F., Letelier, R.M., and Stewart, F.J. (2012) Microbial oceanography of anoxic oxygen minimum zones. Proceedings of the National Academy of Sciences 109: 15996-16003.

Ulloa, O., Wright, J., Belmar, L., and Hallam, S. (2013) Pelagic oxygen minimum zone microbial communities. In E. Rosenberg, E. DeLong, S. Lory, E. Stackebrandt, and F. Thompson (eds.) The Prokaryotes, pp. 113-122. Berlin Heidelberg: Springer.

Vrede, K., Heldal, M., Norland, S., and Bratbak, G. (2002) Elemental composition (C, N, P) and cell volume of exponentially growing and nutrient-limited bacterioplankton. Applied and Environmental Microbiology 68: $2965-2971$.

Walsh, D.A., Zaikova, E., Howes, C.G., Song, Y.C., Wright, J.J., Tringe, S.G., et al. (2009) Metagenome of a versatile chemolithoautotroph from expanding oceanic dead zones. Science 326: 578-582.

Ward, B.B., Kilpatrick, K.A., Novelli, P.C., and Scranton, M.I. (1987) Methane oxidation and methane fluxes in the ocean surface layer and deep anoxic waters. Nature 327: 226 EP.

Wright, J.J., Konwar, K.M., and Hallam, S.J. (2012) Microbial ecology of expanding oxygen minimum zones. Nature Reviews Microbiology 10: 381-394.

Yakushev, E., Pollehne, F., Jost, G., Kuznetsov, I., Schneider, B., and Umlauf, L. (2007) Analysis of the water column oxic/anoxic interface in the Black and Baltic seas with a numerical model. Marine Chemistry 107: $388-410$.

Yakushev, E.V. (2013) RedOx Layer Model: A tool for analysis of the water column oxic/anoxic interface processes, The Handbook of Environmental Chemistry, volume 22, pp. 203-233. Berlin, Heidelberg: Springer Berlin Heidelberg.

Zopfi, J., Ferdelman, T.G., Jorgensen, B.B., Teske, A., and Thamdrup, B. (2001) Influence of water column dynamics on sulfide oxidation and other major biogeochemical processes in the chemocline of Mariager Fjord (Denmark). Marine Chemistry 74: 29-51. 

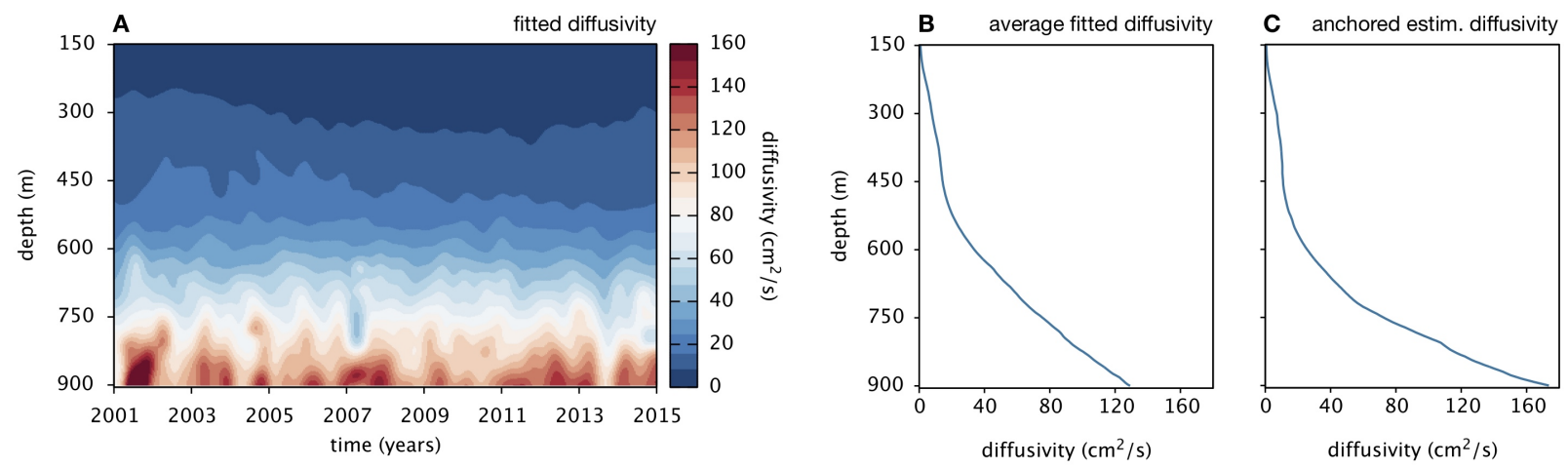

Figure 1: Estimated diffusivity in Cariaco Basin. (A) Diffusivity in Cariaco Basin (station CARIACO) over depth and time, estimated based on the buoyancy frequency, using the power law in Eq. (1) and the fitted parameters $\alpha=$ 0.0001316 and $p=1.7433$. (B) Time-averaged diffusivity depth profile, calculated from A. (C) Estimated diffusivity depth-profile, estimated using Eq. (4) and assuming that $D$ is independent of time. 

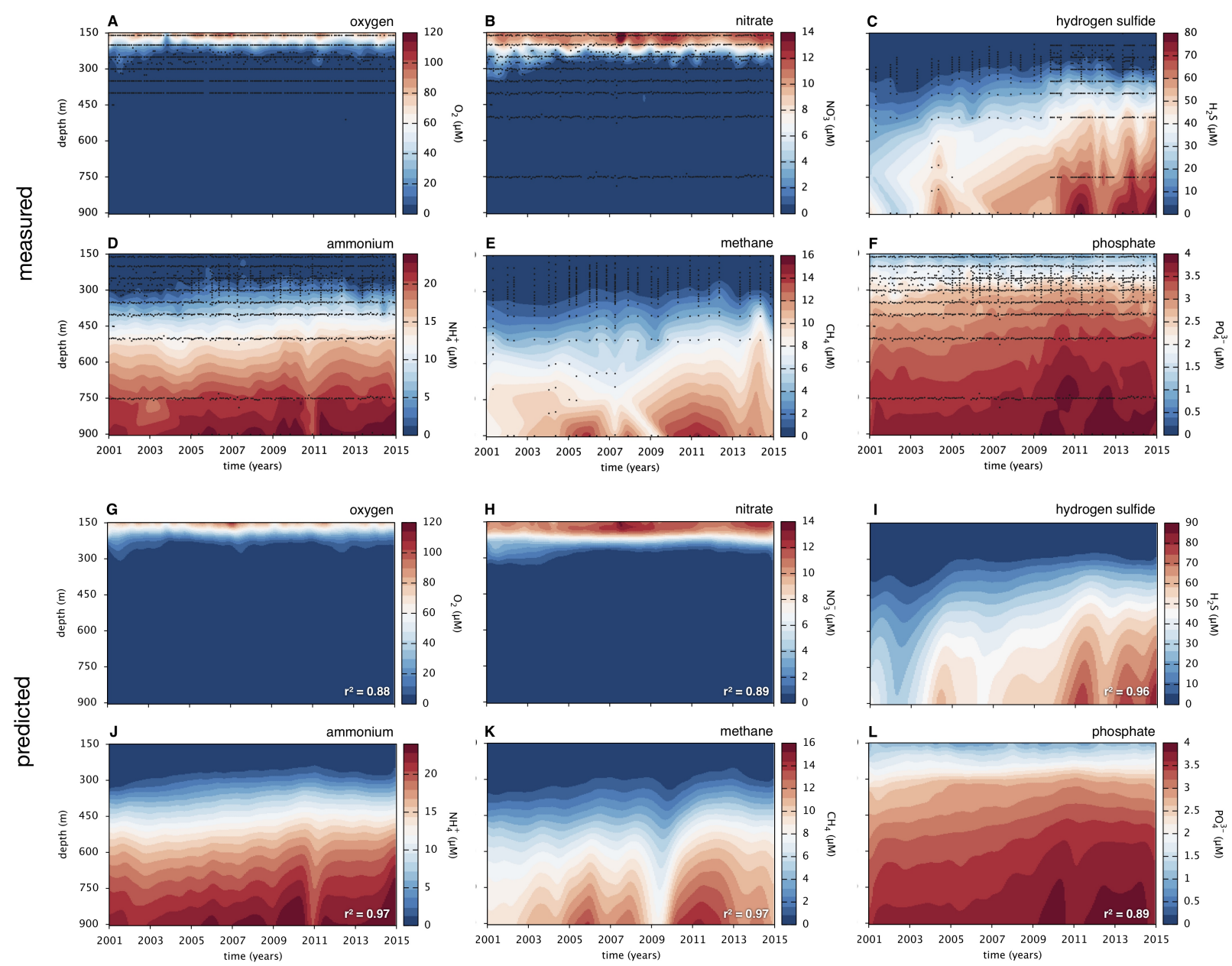

Figure 2: Metabolite concentrations in Cariaco Basin (data versus fitted models). A-F: Measured metabolite concentrations in Cariaco Basin (station CARIACO) over depth and time (A: oxygen, B:nitrate, C:hydrogen sulfide, D:ammonium, E:methane, F:phosphate). Black dots denote data points; contour plots are bilinear interpolations between data points. Data sources are described in the Methods. G-L: Predicted metabolite concentrations, based on the net production rates estimated via ILTM. Fractions of explained variance $\left(r^{2}\right)$, when compared to the data, are indicated in the figures. 

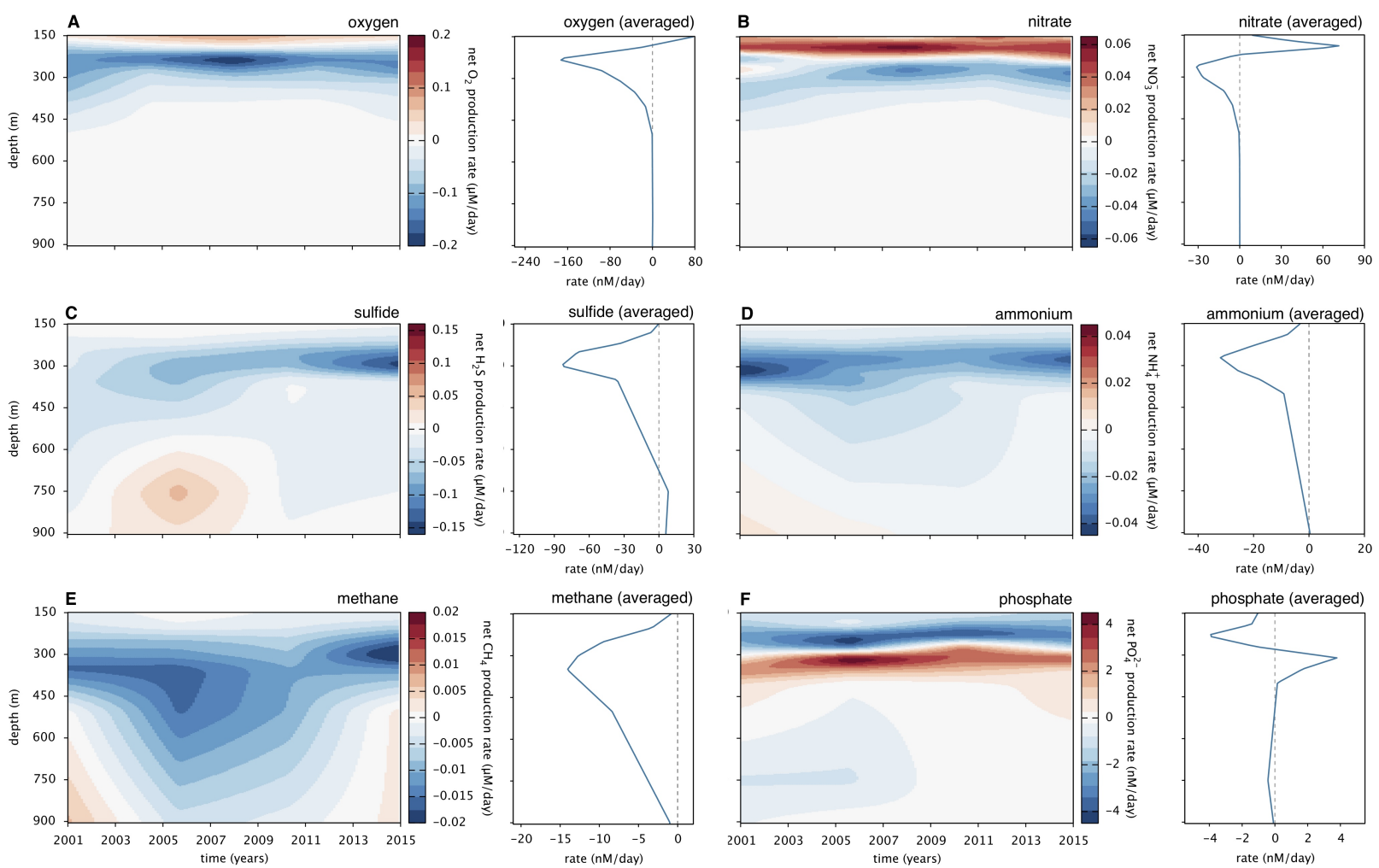

Figure 3: Estimated net metabolite production rates in Cariaco Basin. Volume-specific net metabolite production rates in Cariaco Basin (station CARIACO) over depth and time (contour plots) or averaged over time (depth profiles), estimated via inverse linear transport modeling (A: oxygen, B:nitrate, C:hydrogen sulfide, D:ammonium, E:methane, F:phosphate). In the contour plots, red values correspond to net production, blue values correspond to net consumption, white corresponds to zero net production/consumption. Dashed lines at zero in the time-averaged depth profiles are shown for reference. For estimated gross production and gross consumption rates, see Supplemental Figs. S.8 and S.9, respectively.
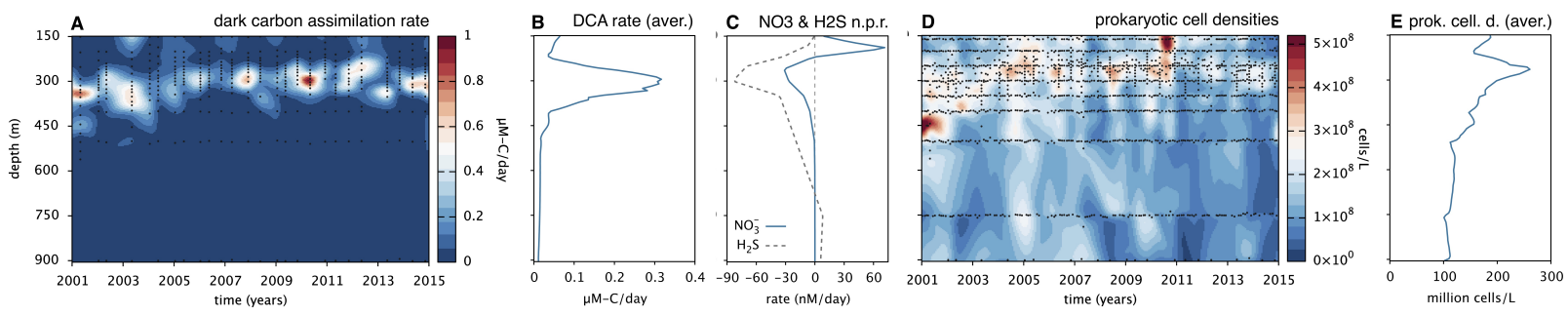

Figure 4: Microbial productivity measured in Cariaco Basin. (A) Dark carbon assimilation (DCA) rate measured in Cariaco Basin (carbon fixed per volume per time) across depth and time. Black dots indicate original data points; the contour plot is obtained via bilinear interpolation. (B) Measured DCA rate, averaged over time (years 2001-2014). (C) Estimated net sulfide and nitrate consumption rates, averaged over time (reproduced from Figs. 3B,C). (D) Measured prokaryotic cell densities (cells per volume) across depth and time. (E) Measured prokaryotic cell densities, averaged over time. Data sources are described in the Methods. For similar figures showing the full water column (including depths $<150 \mathrm{~m}$ and $>900 \mathrm{~m}$ ) see Supplemental Fig. S.5. 
Table 1: Estimated mean metabolite fluxes in Cariaco Basin. Estimated in situ production and consumption rates, as well as influx and outflux rates across the top $(150 \mathrm{~m})$ and bottom boundary $(900 \mathrm{~m})$. The total content is depthintegrated, averaged over the considered time interval (years 2001-2014) and measured in $\mathrm{mol} \cdot \mathrm{m}^{-2}$. All rates are depth-integrated where applicable, averaged over the considered time interval, and measured in $\mathrm{mmol} \cdot \mathrm{m}^{-2} \cdot \mathrm{d}^{-1}$. Depth-integrated or area-specific quantities take into account the variation of the lateral (cross-sectional) basin area with depth, and are normalized to the basin area at depth $150 \mathrm{~m}$ to facilitate comparisons. Mean residence times were estimated based on the depth-integrated concentrations and gross input/output rates, using a non-steady-state box model. See Methods for details. For analogous summaries constrained to after 2009, see Supplemental Table S.1. For analogous summaries constrained to the redoxcline (depths 200-400 m), see Supplemental Table S.2.

\begin{tabular}{lrrrrrr} 
variable & $\mathbf{O}_{\mathbf{2}}$ & $\mathbf{N O}_{\mathbf{3}}^{\mathbf{2}-}$ & $\mathbf{H}_{\mathbf{2}} \mathbf{S}$ & $\mathbf{N H}_{\mathbf{4}}^{+}$ & $\mathbf{C H}_{\mathbf{4}}$ & $\mathbf{P O}_{\mathbf{4}}^{\mathbf{3}-}$ \\
\hline total content (depth-integrated) & 3.5 & 0.81 & 11 & 4.7 & 2.1 & 1.3 \\
gross production rate (depth-integrated) & 2.4 & 2.7 & 1.1 & $<0.1$ & $<0.1$ & 0.17 \\
gross consumption rate (depth-integrated) & 13 & 2.7 & 11 & 4.7 & 3.3 & 0.3 \\
net influx rate at top (150 m) & 7.1 & -0.45 & $<0.1$ & 0.21 & $<0.1$ & -0.077 \\
gross influx rate at top $(150 \mathrm{~m})$ & 7.3 & $<0.1$ & 0.12 & 0.21 & $<0.1$ & $<0.01$ \\
gross outflux rate at top $(150 \mathrm{~m})$ & $<0.1$ & 0.49 & $<0.1$ & $<0.1$ & $<0.1$ & 0.08 \\
net influx rate at bottom (900 m) & $<0.1$ & $<0.1$ & 13 & 5.3 & 3.6 & 0.31 \\
gross influx rate at bottom (900 m) & 0.13 & $<0.1$ & 13 & 5.3 & 3.6 & 0.31 \\
gross outflux rate at bottom (900 m) & 0.17 & $<0.1$ & $<0.1$ & $<0.1$ & $<0.1$ & $<0.01$ \\
net influx rate at top+bottom & 7 & -0.43 & 13 & 5.5 & 3.7 & 0.23 \\
total gross influx+production rate & 9.8 & 2.8 & 14 & 5.5 & 3.8 & 0.48 \\
total gross outflux+consumption rate & 14 & 3.2 & 11 & 4.7 & 3.3 & 0.38 \\
mean residence time (years) & 0.67 & 0.69 & 2.6 & 2.7 & 1.7 & 9.1 \\
\hline
\end{tabular}

